\title{
Prevalence and determinants of hypertension among students of the University of Kinshasa, Democratic Republic of Congo: a cross-sectional study
}

\author{
Guy I Wanghi ${ }^{1}$, Paulin B Mutombo ${ }^{2}$, Ernest K Sumaili ${ }^{1,3}$
}

1. Unit of Physiology, Department of Basic Sciences, Faculty of Medicine, University of Kinshasa, DR Congo.

2. School of Public Health, Faculty of Medicine, University of Kinshasa, DR Congo.

3. Renal unit, Department of Internal Medicine, Faculty of Medicine, University of Kinshasa, DR Congo.

\begin{abstract}
Background: The 2017 ACC/AHA Guideline categorized blood pressure into 4 levels:normal (SBP $<120$ and DBP $<80 \mathrm{~mm}$ $\mathrm{Hg}$ ), elevated (SBP of $120-129$ or $\mathrm{DBP}<80 \mathrm{mmHg}$ ) and stage 1 (SBP of 130-139 or DBP of 80-89 mm Hg) or 2 (SBP $\geq 140$ orDBP $\geq 90 \mathrm{mmHg}$ ). Compared with the JNC7 guideline, the 2017 ACC/AHA guideline recommends using lower SBP and DBP levels to define hypertension.

Objective: To determine the prevalence of hypertension as well as associated factors among students of the University of Kinshasa.

Methods: This was a cross-sectional study conducted at the University of Kinshasa and including 1281 students aged between 18 and 30. Blood pressure was assessed according to the WHO STEPwise approach, which is a standardized method of data collection, analysis and dissemination for the surveillance of non-communicable diseases in WHO member countries. The Chisquare and Student's t-tests and a multivariate logistic regression analysis have been used to evaluate the results. Statistical analyses were done using IBM SPSS version 21.

Results: The prevalence of hypertension according to the guidelines from the 2017 ACC/AHA and the JNC 7 was $26.4 \%$ (CI $95 \% ; 23.9-28.9)$ and $7.3 \%$ (CI 95\%; $5.8-8.8)$, respectively. The results of multivariate logistic regression analysis showed that smoking, alcohol abuse, overweight, male sex, age $\geq 24$ years old and low physical activity were associated with hypertension ( $p$ $<0.0001)$.
\end{abstract}

Conclusion: At least one out of four students had hypertension. These data should encourage public health authorities to develop strategies for screening of BP and topromote the adoption of healthy lifestyle in young adults.

Keywords: Hypertension, risk factors, student, prevalence.

DOI: https://dx.doi.org/10.4314/ahs.v19i4.7

Cite as: Wanghi GI, Mutombo PB, Sumaili EK. Prevalence and determinants of bypertension among students of the University of Kinshasa, Democratic Republic of Congo: a cross-sectional study. Afri Health Sci. 2019;19(4):2854-2862. https:// dx.doi.org/10.4314/ ahs.v19i4.7

\section{Introduction}

The 2017 American College Cardiology/American Heart Association (ACC/AHA) Guideline for the Prevention, Detection, Evaluation and Management of High Blood Pressure in Adults, categorized hypertensives as individuals with systolic blood pressure (SBP) $\geq 130 \mathrm{mmHg}$ or diastolic blood pressure (DBP) $\geq 80 \mathrm{mmHg}^{1}$. This

\section{Corresponding author: \\ Guy I Wanghi, \\ Unit of Physiology, Department of Basic \\ Sciences, Faculty of Medicine, University \\ of Kinshasa, DR Congo. \\ Email: guy.wanghi@unikin.ac.cd, guywanghi2001@yahoo.fr}

guideline updated the Seventh report of the Joint National Committee on Prevention, Detection, Evaluation and treatment on high blood Pressure (JNC7), which was published in $2003^{2}$. Compared with the JNC7 guideline, the 2017 ACC/AHA guideline recommends using lower SBP and DPB levels to define hypertension.

Hypertension has been designated as a silent killer; it presents a significant disease burden on African population $^{3,4}$. Given its magnitude, its excessive financial burden on populations, its severity and growth on a global scale and particularly in sub-Saharan Africa ${ }^{3}$ hypertension is considered a modern epidemic and a major public health problem today.

Hypertension is responsible of around 7.5 million deaths per year worldwide ${ }^{5,6}$, through, mostly, cardiovascular dis-

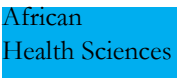

(C) 2019 Wanghi et al. Licensee African Health Sciences. This is an Open Access article distributed under the terms of the Creative commons Attribution License (https://creativecommons.org/licenses/BY/4.0), which permits unrestricted use, distribution, and reproduction in any medium, provided the original work is properly cited. 
eases (CVD), such as coronary heart disease, congestive heart failure, stroke, kidney failure and peripheral arterial disease $e^{5,7}$. Hypertension is the leading cause and risk factor of CVD. The mortality from CVD is expected to increase by $120 \%$ for women and $137 \%$ for men $^{7}$.

Often overlooked, the risk for CVD increases in a log-linear fashion; from SBP levels $<115 \mathrm{~mm} \mathrm{Hg}$ to $>180 \mathrm{~mm}$ $\mathrm{Hg}$, and from DBP levels $<75 \mathrm{~mm} \mathrm{Hg}$ to $>105 \mathrm{~mm} \mathrm{Hg}$. A $20 \mathrm{~mm} \mathrm{Hg}$ higher SBP and $10 \mathrm{~mm} \mathrm{Hg}$ higher DBP are each associated with a doubling in the risk of death from stroke, heart disease, or other vascular disease ${ }^{8}$.

In persons $\geq 30$ years of age, higher SBP and DBP are associated with increased risk for CVD, angina, myocardial infarction (MI), heart failure (HF), stroke, peripheral arterial disease, and abdominal aortic aneurysm. SBP has consistently been associated with increased CVD risk after adjustment for, or within strata of SBP; this is not true for DBP?

Hypertension prevalence in the Democratic Republic of Congo (DRC) has been increasing from 14\% in 1987 to $27.6 \%$ in $2009^{10,11}$.

Studies estimating the prevalence and the determinants of hypertension among youth in the DRC and sub-Saharan Africa are scarce. Those results are needed for planning and implementing preventive strategies in this region as it is happening in other countries such as the young adult population in the U.S ${ }^{12,13}$.

This study was carried out to assess the prevalence of undiagnosed hypertension among students of the University of Kinshasa according to 2017 ACC/AHA guideline, as compared with JNC7 guideline and to identify their associated factors.

\section{Methods}

\section{Data collection}

In this cross-sectional study conducted at the unit of physiology, data collection was open to all students residing in the campus at the University of Kinshasa who consented to be part of the study. In addition, specially assigned people managed quality control. Before the official investigation, a pre-investigation was conducted to explore the design of the questionnaire. An adapted questionnaire was administered to the participants. This questionnaire was structured around three sections: details on socio-demographic, lifestyle (smoking, alcohol use, physical activity) and clinical variables (anthropometric and blood pressure). The data collectors were final medical students and nurses who were systematically trained.
Trained final medical students completed the questionnaires on socio-demographic parameters, lifestyles and anthropometric measures, while trained nurses focused on blood pressure measurements. To ensure that the data collected were high-quality and representative, standard instruments were used, the certification requirements for data collection were strict, and a quality assurance program was conducted.The sample size was calculated as 1281, using the anticipated prevalence of hypertension in the study population as $15 \%$ with $2 \%$ relative precision, 95\% CI, the total regular students of 23700, and a $5 \%$ margin of error. Participants were chosen by doorto-door visits within each of their student residences. The inclusion criteria were: to give informed consent and to be between 18 and 30 years of age. Students who were pregnant and students suffering from a known disease and who were receiving antihypertensive drugs or other medications were excluded from the study.

\section{Measurement of clinical parameters}

The following variables were measured using the WHO STEPS5 requirements adapted to the context of the DRC: weight, height, body mass index (BMI), waist circumference and blood pressure.

Weight was measured using a balance (SECA gmbh Germany Model 7621019009) placed on a stable and level surface and the subject being barefoot and lightly clad.

Height in meters was measured using a portable wall-mounted gauge - subjects were requested to take off their shoes and hats.

The waist circumference was measured along the axillary line at the narrowest part of the abdomen midway between the lower part of the last rib and the upper iliac crest, during exhalation using a new ribbon tape applied to the skin. The measurement was taken only once close to the nearest $0.1 \mathrm{~cm}$.

The BMI was calculated as follows: weight $(\mathrm{kg}) /$ (height (m) $x$ height $(\mathrm{m})$ ).

BP was measured around 7 am before students have gone to school, using an Omron M6 comfort electronic sphygmomanometer (Tokyo, Japan) with an appropriately sized cuff. Cuff size was standard and covering two-thirds of the upper arm and placed at the height of the heart. Readings were obtained after 5 min of seated rest. Tree BP measurements were obtained at 30-s intervals. The mean of the 3 measurements was used to define SBP and $\mathrm{DBP}^{14}$. Participants agreed not to smoke or take caffeinated drinks 30 minutes before the measurement. 


\section{Operational definitions}

-BP categories in the 2017 ACC/AHA guideline are':

- Normal BP: It corresponds to a SBP $<120 \mathrm{mmHg}$ and a DBP < 80 mm Hg;

- Elevated BP: It corresponds to a SBP between 120-129 $\mathrm{mmHg}$ and $\mathrm{aBP}<80 \mathrm{mmHg}$;

- Hypertension stage 1: This stage is characterized by a SBP between $130-139 \mathrm{mmHg}$ or a DBP between $80-89$ $\mathrm{mmHg}$

- Hypertension Stage 2: In this class, the SBP $\geq 140$ or the $\mathrm{DBP} \geq 90 \mathrm{~mm} \mathrm{Hg}$

-According to JNC7 report, BP has been classified as follows ${ }^{2}$.

- Normal BP: It corresponds to a SBP $<120 \mathrm{mmHg}$ and a DBP $<80 \mathrm{mmHg}$;

- Pre-hypertension: It corresponds to a SBP between 120

- $139 \mathrm{mmHg}$ or a DBP between 80 - $89 \mathrm{mmHg}$;

- Hypertension stage 1: This class is characterized by a SBP of $140-159 \mathrm{mmHg}$ or a DBP of $90-99 \mathrm{mmHg}$;

- Hypertension stage 2: In this stage, the SBP $\geq 160$ or the DBP $\geq 100 \mathrm{mmHg}$;

-Pulse pressure (PP): PP is the difference between SBP and DBP;

- Mean arterial pressure (MAP): The MAP is determined as follows: DBP + 1/3 (SBP - DBP);

-For obesity, $\mathrm{BMI} \geq 30 \mathrm{Kg} / \mathrm{m}^{2}$; for overweight, $\mathrm{BMI}=$ $25-29.9 \mathrm{Kg} / \mathrm{m}^{2}$; for normal weight, BMI $=18.5-24.9 \mathrm{Kg}$ / m2; and for thinness: BMI $<18.5 \mathrm{Kg} / \mathrm{m} 2^{15}$.

-Central obesity corresponds to a waist $\geq 94 \mathrm{~cm}$ in men and $\geq 80 \mathrm{~cm}$ in women ${ }^{15}$

-Smoker was defined as a person who at the time of study smoked daily or occasionally and non-smoker, a person who did not smoke at all or smoked 1 year before the study.

-Drinker was defined as one who consumed one or more drinks of any type of alcohol at the time of the study or the year before the study and non-drinker, a person who does not consume alcohol.

-The level of physical activity was defined using the WHO STEP wise approach protocol as follows:

- High: Intense physical activity (PA) at least 3 days a week, entailing higher energy expenditure of at least 1500 MET-minutes / week or at least 7 days walking and moderate or intense PA until a minimum of 3000 MET-minutes per week. MET (Metabolic Equivalent of Task) is a measure of the resting energy expenditure.

- Moderate: A person achieving at least 20 minutes of intense physical activity per day for 3 days or more per week or at least 30 minutes of moderate physical activity or walking per day for 5 days or more per week or at least 5 days walking and moderate or intense PA until reaching a minimum of 600 MET-minutes per week.

- Low: A person who does not meet any of the two criteria mentioned above.

\section{Statistical analysis}

Data were analysed using SPSS version 21.0 (Chicago, USA) and MedCalcR. We described our included sample using frequency (\% proportion) for sex, age groups, grade of study and mean ( \pm standard deviation) for weight, height, systolic blood pressure, diastolic blood pressure, Pulse pressure, average arterial pressure, METs walk ,METs moderate, METs vigorous , METs, Hours of studying and BMI. We categorized BMI into the following groups: $18.5-24.9,25-29.9$, and $\geq 30 \mathrm{Kg} / \mathrm{m}^{2}$. We also categorized blood pressure to normotensive, elevated BP and hypertension.

We used Chi-square test followed by Z-test for proportions to analyse the relation between hypertension status (normotensive, elevated BP and stage 1and 2 hypertension,) and sex and BMI category age groups and grade of study. The strength of association was reported as Odds ratio with a $95 \%$ confidence interval (CI). Logistic regression analysis was applied to study the independent association of risk factors and reported as adjusted OR with IC 95\%.A p value threshold of 0.05 was used.

\section{Ethical consideration}

The protocol was submitted and approved by the national ethics committee. Written informed consent was obtained from the participants after a full explanation of the object and procedure of the study in the traditional language. Those discovered with hypertension during the study were sent to nearby health centers.

\section{Results}

Table 1 presents the general characteristics of subjects. Mean age and body mass index (BMI) of participants were $23.1 \pm 2.7$ years and $22.4 \pm 2.7 \mathrm{~kg} / \mathrm{m}^{2}$, respectively. Males were older than females $(23.4 \pm 3.0$ vs $22.3 \pm 2.2 \mathrm{P}$ $<0.05)$. Men's BMI was higher than that of women $(22.6$ \pm 2.5 vs $22.3 \pm 2.8 \mathrm{p}<0.05)$. The following characteristics: height, SBP, DBP, PP, MAP, and time of study were higher in males than females $(\mathrm{P}<0.0001)$. METs walk, total METs, METs moderate and METs vigorous were not significantly different between the two sexes. 
Table 1: General characteristics of the population studied

\begin{tabular}{|c|c|c|c|}
\hline & $\begin{array}{l}\text { Females } \\
\mathrm{N}=711\end{array}$ & $\begin{array}{l}\text { Males } \\
\mathrm{N}=570\end{array}$ & P value \\
\hline Age (years) & $22.9 \pm 2.3$ & $23.4 \pm 3.0$ & $\mathrm{P}=0.0008$ \\
\hline Weight $(\mathrm{Kg})$ & $57.0 \pm 7.2$ & $65.3 \pm 8.5$ & $\mathrm{P}<0.0001$ \\
\hline Height $(\mathrm{m})$ & $1.60 \pm 0.06$ & $1.70 \pm 0.06$ & $\mathrm{P}<0.0001$ \\
\hline Body mass index (Kg/m2) & $22.3 \pm 2.2$ & $22.6 \pm 2.5$ & $P=0.0459$ \\
\hline Waist circumference $(\mathrm{cm})$ & $74.6 \pm 9.4$ & $76.2 \pm 6.2$ & $\mathrm{P}=0.0005$ \\
\hline Systolic BP (mmHg) & $112.5 \pm 5.0$ & $122.7 \pm 12.1$ & $\mathrm{P}<0.0001$ \\
\hline Diastolic BP (mmHg) & $73.4 \pm 6.2$ & $77.0 \pm 8.9$ & $\mathrm{P}<0.0001$ \\
\hline Pulse pressure $(\mathrm{mmHg})$ & $39.1 \pm 7.0$ & $45.7 \pm 8.6$ & $\mathrm{P}<0.0001$ \\
\hline Average arterial pressure $(\mathrm{mmHg})$ & $86.4 \pm 6.5$ & $92.2 \pm 9.2$ & $\mathrm{P}<0.0001$ \\
\hline METs walk & $653.3 \pm 198.3$ & $662.7 \pm 271.1$ & $\mathrm{P}=0.0001$ \\
\hline METs moderate & $715.0 \pm 411.3$ & $687.3 \pm 411.3$ & $\mathrm{P}=0.8330$ \\
\hline METs vigorous & $1520.5 \pm 826.8$ & $1043.20 \pm 956.2$ & $P=0.2631$ \\
\hline METs & $735.2 \pm 340.6$ & $772.5 \pm 449.8$ & $\mathrm{P}=0.0001$ \\
\hline Hours of studying (minutes/week) & $397.3 \pm 35$ & $375.0 \pm 54.0$ & $\mathrm{P}<0.0001$ \\
\hline \multicolumn{4}{|l|}{ Age Groups $n(\%)$} \\
\hline $18-23$ years & $412(32.2 \%)$ & $319(24 . .9 \%)$ & $\mathrm{P}>0.05^{*}$ \\
\hline $24-30$ years & $299(23.3 \%)$ & $251(19.6 \%)$ & \\
\hline \multicolumn{4}{|l|}{ Grade of study n(\%) } \\
\hline $1^{\text {st }}-3^{\text {rd }}$ grade & $478(37.3 \%)$ & $427(33.3 \%)$ & $\mathrm{P}<0.05^{* *}$ \\
\hline $4^{\text {th }}-7^{\text {th }}$ grade & $233(18.2 \%)$ & $143(11.2 \%)$ & \\
\hline
\end{tabular}

Table 2 shows that the prevalence of hypertension according to the ACC/AHA guideline in the population studied was $26.4 \%$ (CI 95\%; 23.9 - 28.9). This prevalence was higher among men than women $(47.2 \%$ vs.
$9.7 \%),(p<0.0001)$. When age groups were considered, hypertension had higher values in subjects with age $\geq 24$ years than those of age $\leq 23$ years ( $35.8 \%$ vs. $19.3 \%)$, (p $<0.0001)$.

Table 2: Prevalence of hypertension according to the ACC/AHA guideline by sex, age, grade of study and BMI

\begin{tabular}{|c|c|c|c|c|c|}
\hline & $\begin{array}{l}\text { Whole group } \\
\mathrm{N}=1281\end{array}$ & $\begin{array}{l}\text { Normal BP } \\
N=784\end{array}$ & $\begin{array}{l}\text { Elevated BP } \\
\mathrm{N}=159\end{array}$ & $\begin{array}{l}\text { Hypertension } \\
\mathrm{N}=338\end{array}$ & P value \\
\hline Sex & & & & & $\mathrm{P}<0.0001$ \\
\hline Females & $711(55.5 \%)$ & $603(84.8 \%)$ & $38(5.5 \%)$ & $69(9.7 \%)$ & \\
\hline Males & $570(44.5 \%)$ & $181(31.8 \%)$ & $120(21.1 \%)$ & $269(47.2 \%)$ & \\
\hline Group of age & & & & & $\mathrm{P}<0.0001$ \\
\hline $18-23$ years & $731(57.1 \%)$ & $525(71.8 \%)$ & $65(8.9 \%)$ & $141(19.3 \%)$ & \\
\hline $24-30$ years & $550(42.7 \%)$ & $259(42.1 \%)$ & $94(17.1 \%)$ & $197(35.8 \%)$ & \\
\hline Grade of study & & & & & $\mathrm{P}<0.0001$ \\
\hline $1^{\text {st }}-3^{\text {rd }}$ grade & $905(70.6 \%)$ & $592(65.4 \%)$ & $102(11.3 \%)$ & $211(23.3 \%)$ & \\
\hline $4^{\text {th }}-7^{\text {th }}$ grade & $376(29.4 \%)$ & $192(51.0 \%)$ & $57(15.2 \%)$ & $127(33.8 \%)$ & \\
\hline $\mathrm{BMI}\left(\mathrm{Kg} / \mathrm{m}^{2}\right)$ & & & & & $\mathrm{P}<0.0001$ \\
\hline$<18.5$ & $(4.1 \%)$ & $42(80.8 \%)$ & $1(1.9 \%)$ & $9(17.3 \%)$ & \\
\hline $18.5-24.9$ & $1042(81.3 \%)$ & $667(64.0 \%)$ & $125(12.0 \%)$ & $250(24.0 \%)$ & \\
\hline $25-29.9$ & $165(12.9 \%)$ & $68(41.2 \%)$ & $31(18.8 \%)$ & $66(40.0 \%)$ & \\
\hline$\geq 30$ & $22 \quad(1.7 \%)$ & $7(31.8 \%)$ & $2(9.1 \%)$ & $13(59.1 \%)$ & \\
\hline Total & $1281(100 \%)$ & $784(61.2)$ & $159(12.4 \%)$ & $338(26.4 \%)$ & \\
\hline
\end{tabular}


Comparison of normal blood pressure to both hypertension and normal blood pressure by sex, age group showed a statistically significant difference $(p<0.0001)$. Student's and Fischer's tests were used to compare those with hypertension vs. elevated BP, normal blood pressure vs. elevated blood pressure and normal blood pressure VAs. hypertension by gender, age group and grade of study and showed a statistically significant difference $(p<0.0001)$. ACC/AHA and JNC7 guideline definitions respectively (table 3). The prevalence of hypertension was higher when defined by the 2017 ACC/AHA guideline com- pared with the JNC guideline within all sex, age, BMI and grade of study. When hypertension was compared according the 2017ACC/AHA and JNC 7 guidelines definitions between sex, group of age, grade of study and BMI, hypertension was higher in the males ( $47.2 \%$ vs $9.7 \%$ for 2017 ACC/AHA and $13.0 \%$ vs 6.9 for JNC 7), $4^{\text {th }}-7^{\text {th }}$ grade $(33.8 \%$ vs $23.3 \%$ for 2017 ACC/AHA and $11.4 \%$ vs 5.6 for JNC 7 ), $24-30$ years(35.8 \% vs $19.3 \%$ for 2017 ACC/AHA and $11.6 \%$ vs 4.1 for JNC 7 ) and BMI $\geq 30(59.1 \%$ vs $40.0 \%, 24.0 \%$ and $17.3 \%$ for 2017 ACC/ AHA and $45.5 \%$ vs $17.0 \%, 5.3 \%$ and $1.9 \%$ for JNC 7 ).

Table 3. Proportion of students with hypertension according to the 2017 ACC/AHA and the JNC 7 Guidelines

\begin{tabular}{|c|c|c|c|}
\hline & $\begin{array}{c}2017 \text { ACC/AHA } \\
\text { Guideline }\end{array}$ & $\begin{array}{l}\text { JNC } \\
2003\end{array}$ & $\begin{array}{c}2017 \text { ACC/AHA } \\
\text { Guideline But Not } \\
\text { JNC Guideline }\end{array}$ \\
\hline Overall & $26.4(23.9-28.9)$ & $7.3(5.8-8.8)$ & $19.1(17.0-21.2)$ \\
\hline \multicolumn{4}{|l|}{ Sex } \\
\hline Females & $9.7 \quad(7.5-11.9)$ & $2.8(1.6-4.0)$ & $6.9(5.5-8.3)$ \\
\hline Males & $47.2(43.0-51.4)$ & $13.0(10.2-15.8)$ & $34.2(31.6-36.8)$ \\
\hline \multicolumn{4}{|l|}{ Grade of study } \\
\hline 1 st -3 rd grade & $23.3(20.5-26.1)$ & $5.6(4.1-7.1)$ & $17.7(15.6-19.8)$ \\
\hline 4 th -7 th grade & $33.8(28.9-38.7)$ & $11.4(8.1-14.7)$ & $22.4(20.1-24.7)$ \\
\hline \multicolumn{4}{|l|}{ BMI (Kg/m2) } \\
\hline$<18.5$ & $17.3(6.9-28.0)$ & $1.9(1.7-5.5)$ & $15.4(13.4-17.4$ \\
\hline $18.5-24.9$ & $24.0(21.4-26.6)$ & $5.3(3.9-6.7)$ & $18.7(16.6-20.8)$ \\
\hline $25-29.9$ & $40.0(32.4-47.6)$ & $17.0(11.2-22.2)$ & $23.0(19.7-25.3)$ \\
\hline$\geq 30$ & $59.1(30.1-88.2)$ & $45.5(24.5-66.5)$ & $13.6(11.7-15.5)$ \\
\hline \multicolumn{4}{|l|}{ Group of age } \\
\hline $18-23$ years & $19.3(16.4-22.2)$ & $4.1(2.6-5.6)$ & $15.2(13.2-17.2)$ \\
\hline $24-30$ years & $35.8(31.7-39.9)$ & $11.6(8.9-14.3)$ & $24.2(21.8-26.6)$ \\
\hline
\end{tabular}

Values are $\%$ of students with hypertension (95\% Confidence interval)

ACC $/ \mathrm{AHA}=$ American College of Cardiology/American Heart Association

JNC7 $=$ Seventh Report of the Joint National Committee on Prevention, Detection, Evaluation and treatment of High Blood Pressure

$\mathrm{BMI}=$ Body mass index

A binary logistic regression analysis was performed using SPPS to assess significant determinants of hypertension according to the 2017 ACC/AHA and JNC 7 guideline definitions. The results are shown in table 4 and 5 . The risk of hypertension according to the 2017ACC/AHA and JNC 7 guideline definitions was very high in males, overweight; students aged $\geq 24$ years, $4^{\text {th }}-7$ th grade students and students with high physical activity. Smokers and alcohol consumers, low physical activity had a high risk of having hypertension compared to non-smokers, non-consumers of alcohol and no low physical activity. Therefore for the model fit, the risk factors for hypertension according to the 2017 ACC/AHA guideline were the male sex associated with the age $\geq 24$ years, smoking, overweight, low physical activity. Smoking associated with overweight, male sex and alcohol intake, low physical activity was shown to model fit as risk factors for high blood pressure according JNC7. 
Table 4: Logistic regression analysis showing the association between hypertension and sociodemographic and lifestyle risk factors according to the 2017 ACC/AHA guideline

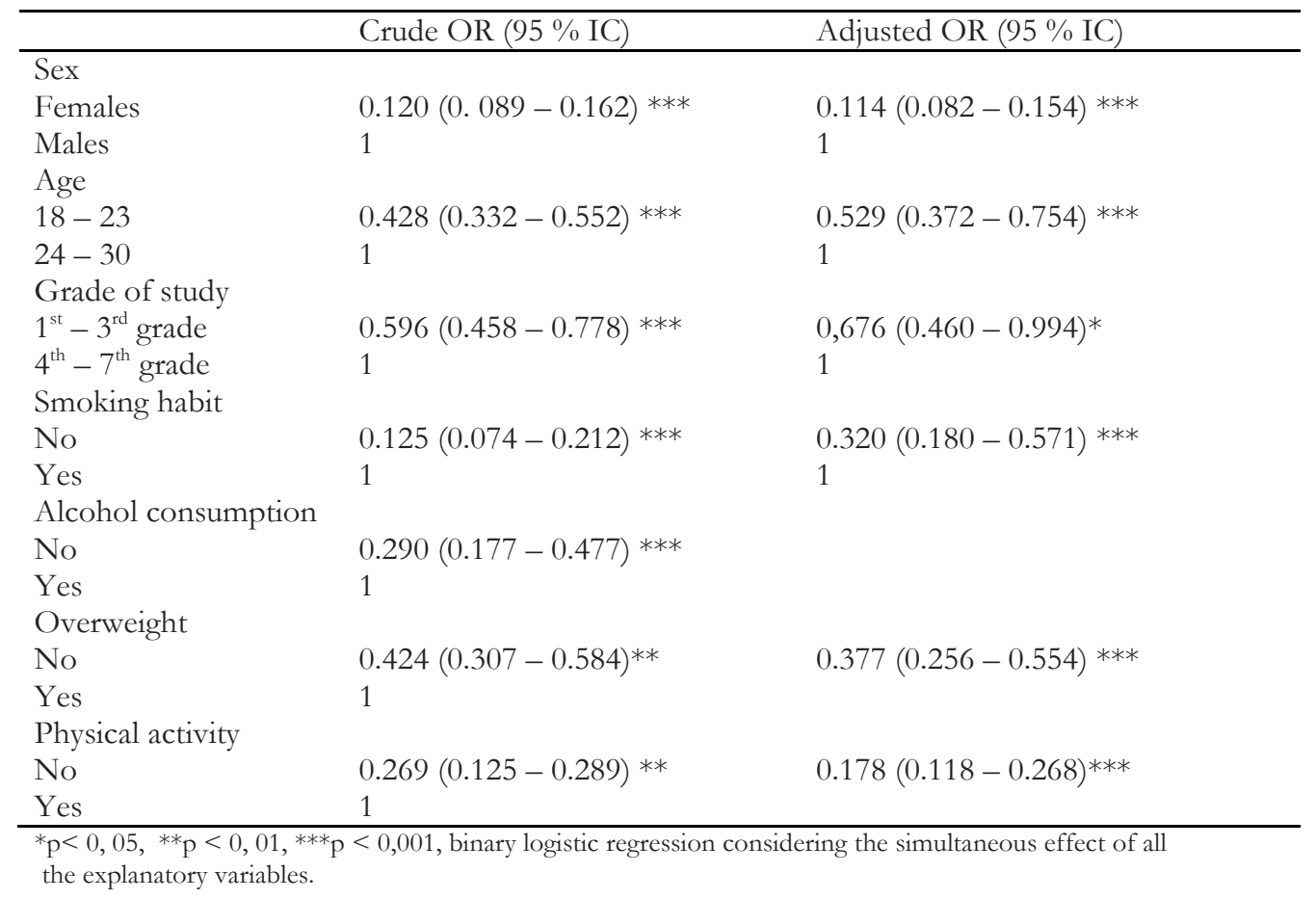

Table 5: Logistic regression analysis of the association between hypertension and socio-demographic and lifestyle risk factors according the JNC 7 guideline

\begin{tabular}{|c|c|c|}
\hline & Crude OR (95\% IC) & Adjusted OR (95\% IC) \\
\hline \multicolumn{3}{|r|}{ (2) } \\
\hline Females & $0.194(0.117-0.322) * * *$ & $0.286(0.165-0.498)$ *** \\
\hline Males & 1 & 1 \\
\hline \multicolumn{3}{|l|}{ Age } \\
\hline $18-23$ & $0.325(0.207-0.509) * *$ & $0.527(0.320-0.870) *$ \\
\hline $24-30$ & 1 & 1 \\
\hline \multicolumn{3}{|l|}{ Smoking habit } \\
\hline No & $0.064(0.038-0.109)^{* * *}$ & $0.120(0.064-0.225)^{* * *}$ \\
\hline Yes & 1 & 1 \\
\hline \multicolumn{3}{|l|}{ Alcohol consumption } \\
\hline No & $0.290(0.177-0.477)^{* *}$ & $0.476(0.259-0.877)^{*}$ \\
\hline Yes & 1 & 1 \\
\hline \multicolumn{3}{|l|}{ Overweight } \\
\hline No & $0.212(0.135-0.331)^{* * *}$ & $0.166(0.99-0.280)$ \\
\hline Yes & 1 & 1 \\
\hline \multicolumn{3}{|l|}{ Grade of study } \\
\hline $1^{\text {st }}-3^{\text {rd }}$ grade & $0.665(0.516-0.858)^{*}$ & \\
\hline $4^{\text {th }}-7^{\text {th }}$ grade & 1 & \\
\hline \multicolumn{3}{|l|}{ Overweight } \\
\hline No & $0.212(0.135-0.331)^{* * *}$ & $0.166(0.99-0.280)$ \\
\hline Yes & 1 & 1 \\
\hline \multicolumn{3}{|l|}{ Physical activity } \\
\hline Low physical activity & $0.685(0.542-0.869)^{*}$ & $0.765(0.632-0.863)$ \\
\hline $\begin{array}{l}\text { No low physical } \\
\text { activity }\end{array}$ & 1 & 1 \\
\hline
\end{tabular}




\section{Discussion}

In this cross-sectional study, we found that if we were to apply the most recent threshold for the diagnosis of hypertension, $26.4 \%$ of our university students will be diagnosed with hypertension (i.e., systolic blood pressure $>130 \mathrm{mmHg}$ and diastolic blood pressure $>80 \mathrm{mmHg}$ ) compared to $7.3 \%$ using the previous guidelines (i.e., systolic blood pressure $>140 \mathrm{mmHg}$ and diastolic blood pressure $>90 \mathrm{mmHg}$ ).Moreover, we found significant gender differences in both systolic blood pressure with mean difference $=10.2 \mathrm{mmHg}$ and diastolic blood pressure with mean difference $=3.6 \mathrm{mmHg}$, higher in males than in females.

Several studies conducted in academic institutions demonstrated that high blood pressure was a major health problem among students over the age of $18^{16-20}$. The prevalence of hypertension of $26.4 \%$ found in this study according to the 2017 ACC/AHA was higher when compared with the JNC 7 guideline $(26.4 \%$ vs $7.3 \%)$. We estimate that the 2017 ACC/AHA hypertension guideline will result in a substantial increase in the proportion of students defined as having hypertension in this study. This increase is explained following a difference in the categorization of hypertension. Stage 1 is defined in 2017 ACC/AHA report as a SBP between 130 and $139 \mathrm{mmHg}$ or a DBP between 80 and $89 \mathrm{mmHg}$ whereas a stage 2 hypertension corresponds to stages 1 and 2 in the JNC 7 report. However, non pharmacological therapy on its own is the recommended treatment for the adults with SBP/DBP of 130 to $139 / 80$ to $89 \mathrm{~mm} \mathrm{Hg}$. The 2017 ACC/AHA guideline writing committee concluded that there is insufficient evidence to support a recommendation for antihypertensive drug treatment in addition to nonpharmacological therapy for adults with SBP/DBP of 130 to $139 / 80$ to $90 \mathrm{~mm} \mathrm{Hg}$ and low CVD risk. As a consequence, the new definition results in only a small increase in the percentage of students for whom antihypertensive medication is recommended in conjunction with lifestyle modification.

The present study showed a positive association between sex and hypertension. Indeed the prevalence of hypertension is generally higher in males than in the females ${ }^{16,20,21}$. This information is similar to that reported in several studies showing that the blood pressure of young men is higher than that of young women (age $\leq 30$ years) $)^{16,18}$. Young men generally have high blood pressure compared to young women and older men have a generally lower blood pressure compared to elderly women because it is known that menopause and overweight can increase the risk of hypertension ${ }^{23}$. This study also showed that the prevalence of hypertension increased with age, the prevalence of hypertension was low in the age group of 18 to 23 compared to the age group of 24 to 30 . Previous studies by other authors confirm these results ${ }^{23,24}$. In addition, it is important to mention that those who are overweight had a high risk of developing hypertension compared to subjects with normal BMI. This was in line with previous reports from countries in sub-Saharan Africa ${ }^{24}$, India ${ }^{26}$ and Portugal ${ }^{18}$. In the latter study, $68 \%$ of hypertensive patients were overweight. In the present cross-sectional study, the risk factors associated with hypertension were age, sex, physical inactivity, alcohol consumption, smoking habit and BMI. The male sex, age $\geq 24$, low physical activity and overweight were the predictors of high blood pressure among students who participated in this study. These results corroborate those found by other authors $^{23,27}$. The new guideline stated that some of the diet-related factors associated with high BP include overweight and obesity, excess intake of sodium, and insufficient intake of potassium, calcium, magnesium, protein (especially from vegetables), fiber, and fish fats. Poor diet, physical inactivity, and excess intake of alcohol, alone or in combination, are the underlying causes of a large proportion of hypertension ${ }^{28,29}$.

The prevalence of $26.4 \%$ and $7.3 \%$ of hypertension according to 2017 ACC/AHA and JNC7 guidelines respectively among students aged 18 to 30 at the University of Kinshasa with the associated risk factors should be a wakeup call for the public authorities to implement screening strategies in universities and all segments of the Congolese population in this age group. Public health authorities should develop projects that encourage young adults to modify their lifestyles regarding personal habits (use of alcohol and tobacco), eating habits and physical activity because hypertension among university students is not really taken into consideration and will only be discovered later. Since students seem to be generally healthy, they may not see the need to visit a doctor for a routine checkup. This may explain why hypertension is discovered late among university students. In addition students must reduce sodium intake and increase potassium consumption as recommended by the 2017 guide- 
line, because blacks are particularly sensitive to salt ${ }^{30}$. This sensitivity to salt can be a marker of increased risk of CVD and all-cause mortality, regardless of blood pressure $^{31}$. Yet data on the prevalence of hypertension and other chronic non-communicable diseases are needed for planning, prevention and evidence to be used in resource mobilization ${ }^{12}$. Data from the present study draw attention to the importance of blood pressure screening programs among young adults.

\section{Limitations and strengths}

The results should also be interpreted in the context of known and potential limitations. Our study is of a cross-sectional nature, which means that the associations between study variables may not involve causality. Certain variables such as tobacco use, alcohol consumption were measured only in terms of frequency and not quantity. Data on the family history of hypertension were not taken into account. BP was measured at a single visit in this study. The 2017 ACC/AHA and the JNC7 guidelines suggest basing the diagnosis of hypertension on the average of multiple BP measurements obtained at 2 or more visits. Despite these limitations, our sample size was large. The present study suggests that there is great potential for decreasing cardiovascular morbidity or mortality by optimizing modifiable risk factors in this young population.

\section{Conclusion}

In our study, $26.4 \%$ and $7.3 \%$ of students of the University of Kinshasa had hypertension according the 2017 ACC/AHA guideline and JNC7 respectively. Overweight, age group 24-30, male, lifestyle (alcohol and tobacco) and low physical activity appeared to significantly influence the presence of hypertension in these young adults. These results provide preliminary data on the high proportion of hypertension and its associated risk factors among students at the University of Kinshasa.These findings indicate that earlier detection and intervention should be carried out as soon as possible within the university setting and among the general public. In order to increase awareness of hypertension and other health-related issues, more promotions can be carried out using electronic media and social media networking.

\section{Acknowledgments}

We thank all students from the University of Kinshasa who accepted to participate in this study. We also thank the professor Benedicta N. NKEH-Chungag of the Walter Sisulu University in South Africa for her critical review of this manuscript. This work was financially supported by the University of Kinshasa.

\section{Conflict of interest}

None declared.

\section{References}

1. Whelton PK, Carey RM, Aronow WS, Casey DE, Jr., Collins KJ, Dennison Himmelfarb C, DePalma SM, Gidding S, Jamerson KA, Jones DW et al: ACC/AHA/ AAPA/ABC/ACPM/AGS/APhA/ASH/ASPC/NMA/ PCNA Guideline for the Prevention, Detection, Evaluation, and Management of High Blood Pressure in Adults: A Report of the American College of Cardiology/American Heart Association Task Force on Clinical Practice Guidelines. J Am Coll Cardiol 2017, 138 (17):426-483.

2. Chobanian AV, Bakris GL, Black HR, Cushman WC, Green LA, Izzo JL, Jr., Jones DW, Materson BJ, Oparil S, Wright JT, Jr. et al: The Seventh Report of the Joint National Committee on Prevention, Detection, Evaluation, and Treatment of High Blood Pressure: the JNC 7 report. JAMA 2003, 289(19):2560-2572.

3. Hendriks ME, Wit FW, Roos MT, Brewster LM, Akande TM, de Beer IH, Mfinanga SG, Kahwa AM, Gatongi P, Van Rooy $G$ et al: Hypertension in sub-Saharan Africa: cross-sectional surveys in four rural and urban communities. PLoS One, 20097(3):e32638.

4. van der Sande MA, Milligan PJ, Nyan OA, Rowley JT, Banya WA, Ceesay SM, Dolmans WM, Thien T, McAdam KP, Walraven GE: Blood pressure patterns and cardiovascular risk factors in rural and urban gambian communities. J Hum Hypertens 2000, 14(8):489-496.

5. Mendis S, Davis S, Norrving B: Organizational update: the world health organization global status report on noncommunicable diseases ; one more landmark step in the combat against stroke and vascular disease. Stroke 2014, 46(5):e121-122.

6. Mathers C SG, Mascarenhas M: Global health risks: Mortality and burden of disease attributable to selected major risks. Geneva, Switzerland: World Health Organization. 2009.

7. Kearney PM, Whelton M, Reynolds K, Muntner P, Whelton PK, He J: Global burden of hypertension: analysis of worldwide data. Lancet 2005, 365(9455):217-223.

8. Lewington S, Clarke R, Qizilbash N, Peto R, Collins $\mathrm{R}$ : Age-specific relevance of usual blood pressure to 
vascular mortality: a meta-analysis of individual data for one million adults in 61 prospective studies. Lancet 2002, 360(9349):1903-1913.

9. Rapsomaniki E, Timmis A, George J, Pujades-Rodriguez M, Shah AD, Denaxas S, White IR, Caulfield MJ, Deanfield JE, Smeeth L et al: Blood pressure and incidence of twelve cardiovascular diseases: lifetime risks, healthy life-years lost, and age-specific associations in 1.25 million people. Lancet, 383(9932):1899-1911.

10. Sumaili EK, Krzesinski JM, Zinga CV, Cohen EP, Delanaye P, Munyanga SM, Nseka NM: Prevalence of chronic kidney disease in Kinshasa: results of a pilot study from the Democratic Republic of Congo. Nephrol Dial Transplant 2009, 24(1):117-122.

11. Lulebo AM, Mapatano MA, Kayembe PK, Mafuta EM, Mutombo PB, Coppieters Y: Assessment of hypertension management in primary health care settings in Kinshasa, Democratic Republic of Congo. BMC Health Serv Res 2015, 15:573.

12. Maher D, Waswa L, Baisley K, Karabarinde A, Unwin N, Grosskurth H: Distribution of hyperglycaemia and related cardiovascular disease risk factors in low-income countries: a cross-sectional population-based survey in rural Uganda. Int J Epidemiol 2010, 40(1):160-171.

13. Fang J, Wang G, Ayala C, et al. Healthcare access among young adults: impact of the Affordable Care Act on young adults with hypertension. Am J Prev Med 2017;53:S213-9

14. NHANES 1999-2002 addendum to the NHANES III analytic guidelines. 2002. Available at: http://www. cdc.gov/nchs/data/nhanes/guidelines1.pdf. Accessed April 6, 2018.

15. Du T, Sun X, Yin P, Huo R, Ni C, Yu X: Increasing trends in central obesity among Chinese adults with normal body mass index, 1993â€"2009. BMC Public Health 2013, 13:327.

16. Nkeh-Chungag BN, Mxhosa TH, Mgoduka PN: Association of waist and hip circumferences with the presence of hypertension and pre-hypertension in young South African adults. Afr Health Sci 2015, 15(3):908-916.

17. Tadesse T, Alemu H: Hypertension and associated factors among university students in Gondar, Ethiopia: a cross-sectional study. BMC Public Health 2014, 14:937

18. Dores H, Santos P, Salvador F, Maia J, Paixao L, Pereira R, Goncalves N, Leitao A, Fonseca C, Ceia F: Blood pressure in young adults. Rev Port Cardiol 2010, 29(10):1495-1508.

19. : Losimba L.J. MS, Abi Y., Batina A.S., :Fréquence de l'hypertension et facteurs de risque parmi les étudiants du département de Santé Publique de l'Université de Kisangani, RDC. KisMéd Aout 2014, Vol 5(1) : 2-8.

20. Al-Majed HT, Sadek AA: Pre-hypertension and hypertension in college students in Kuwait: a neglected issue. J Family Community Med 2012, 19(2):105-112.

21. Aounallah-Skhiri H, El Ati J, Traissac P, Ben Romdhane H, Eymard-Duvernay S, Delpeuch F, Achour N, Maire B: Blood pressure and associated factors in a North African adolescent population. a national cross-sectional study in Tunisia. BMC Public Health 2012, 12:98.

22. Calhoun DA, Harding SM: Sleep and hypertension. Chest 2010, 138(2):434-443.

23. Tabrizi JS, Sadeghi-Bazargani H, Farahbakhsh M, Nikniaz L, Nikniaz Z: Prevalence and Associated Factors of Prehypertension and Hypertension in Iranian Population: The Lifestyle Promotion Project (LPP). PLoS One 2018, 11(10):e0165264.

24. Jayawardene WP, Lohrmann D, Dickinson S, Talagala S, Torabi M: Clinical measures of obesity and cumulative cardiometabolic risk in adolescents. Clin Obes.

25. Bosu WK: The prevalence, awareness, and control of hypertension among workers in West Africa: a systematic review. Glob Health Action 2015, 8:e26227.

26. Todkar SS, Gujarathi VV, Tapare VS: Period prevalence and sociodemographic factors of hypertension in rural maharashtra: a cross-sectional study. Indian J Community Med 2009, 34(3):183-187.

27. Isezuo SA, Sabir AA, Ohwovorilole AE, Fasanmade OA: Prevalence, associated factors and relationship between prehypertension and hypertension: a study of two ethnic African populations in Northern Nigeria. J Hum Hypertens 2011, 25(4):224-230.

28. Savica V, Bellinghieri G, Kopple JD: The effect of nutrition on blood pressure. Annu Rev Nutr 2010, 30:365401.

29. Chan Q, Stamler J, Griep LM, Daviglus ML, Horn LV, Elliott P: An Update on Nutrients and Blood Pressure. J Atheroscler Thromb 2016,23(3):276-289.

30. Rodrigues SL, Baldo MP, Machado RC, Forechi L, Molina Mdel C, Mill JG: High potassium intake blunts the effect of elevated sodium intake on blood pressure levels. J Am Soc Hypertens 2014, 8(4):232-238.

31. Elijovich F, Weinberger MH, Anderson CA, Appel LJ, Bursztyn M, Cook NR, Dart RA, Newton-Cheh CH, Sacks FM, Laffer CL: Salt Sensitivity of Blood Pressure: A Scientific Statement From the American Heart Association. Hypertension 2016, 68(3):e7-e46. 